\title{
THE ANALYSIS OF VERTICAL HYDRAULIC CONDUCTIVITY OF THE RIVERBED OVER TIME - A CASE STUDY OF DOWNSTREAM OF ZIARAT RIVER, NORTHERN IRAN
}

\author{
BORNA, M. R. ${ }^{1}-$ JAVID, A. H. $.^{2^{*}}-$ SADEGHIAN, M. S. ${ }^{1}-$ MIRBAGHERI, S. A. ${ }^{3}$ \\ ${ }^{1}$ Department of Civil Engineering, Faculty of Engineering, Tehran Central Branch, Islamic \\ Azad University, Tehran, Iran \\ ${ }^{2}$ Department of Environmental Engineering, Graduate School of Natural Resources and \\ Environment, Science and Research Branch, Islamic Azad University, Tehran, Iran \\ ${ }^{3}$ Civil and Environmental Engineering Faculty, Khaje Nasir Toosi University of Technology, \\ Tehran, Iran \\ *Corresponding author \\ e-mail: a.javid@srbiau.ac.ir; phone:+98-912-103-7369; fax:+98-21-4486-5010 \\ (Received 23 $3^{\text {rd }}$ Mar 2018; accepted $12^{\text {th }}$ Jun 2018)
}

\begin{abstract}
Vertical hydraulic conductivity $\left(\mathrm{K}_{\mathrm{v}}\right)$ of riverbed is an important variable exerting impact on the exchange of water and salts between riverbeds and the surrounding underground water systems. However, there is little detailed information on the spatial variations of the riverbed $K_{v}$, and there is hardly any information on its timing variations. Time changes in the amount of $\mathrm{K}_{\mathrm{v}}$ of the riverbed reveal the need for further studies as a potentially significant controlling factor in temporal variations in the amount and spatial patterns of water fluxes and solutes between groundwater and surface waters. With this in view, this study adopted a time series analysis approach to investigate the hydraulic conductivity measured over a year from January 2016 to January 2017 on a weekly basis for a downstream point of the Gorgan Ziarat River, Iran. The researchers first began to verify the hydraulic conductivity data, which was a downward trend during this period, from the particle size distribution of the riverbed for several times over the course of a year. Then, after identifying the existing data trends, autocorrelation and partial autocorrelation coefficients were determined. Finally, an ARMA model $(1,1)$ was identified as the superior model. The mean squared error was used to evaluate the selected model. Moreover, Pert-Manto test was used to test the validity and reliability of the model.
\end{abstract}

Keywords: riverbed, downstream, particle size, time series analysis, ARMA models

\section{Introduction}

Hydraulic conductivity $\left(\mathrm{K}_{\mathrm{v}}\right)$ of streambed is regarded as one of the most important controlling variables in the exchange of water and minerals between the rivers and the surrounding groundwater systems (Saenger et al., 2005; Storey et al., 2003). Variations in the location of $K_{v}$ of the streambed may lead to increase in the water exchange rate between one stream and the Hyporheic region of the bed, which can lead to changes in the durability of the minerals and further cause intermixture in this area (Cardenas et al., 2004). Little information is available about the way such aspects of the exchange between the streambed and groundwater may be affected by the temporal changes of the $\mathrm{K}_{\mathrm{v}}$ of the streambed.

Hydraulic conductivity $\left(\mathrm{K}_{\mathrm{v}}\right)$ of streambed is an effective variable in the exchange of water and minerals between the rivers and the surrounding groundwater systems. There exists little information about the environmental changes of the $\mathrm{K}_{\mathrm{v}}$ of the streambed and almost no information on its temporal changes. The environmental and temporal 
variation of $\mathrm{K}_{\mathrm{v}}$ of a river in North Carolina during a one-year period was studied using 487 field measurements (Genereux et al., 2008).

The temporal changes of streambed's $\mathrm{K}_{\mathrm{v}}$ determine further studies as a potential controlling factor in the temporal changes of amount and environmental patterns of water and the minerals between the groundwater and surface water. Using the available information, it seems appropriate to consider the streambed's $\mathrm{K}_{\mathrm{v}}$ as a dynamic feature which is dynamic both in terms of time and location.

A pilot area (11.42 km in length) in Pajaro River located in the central beach of California was studied using the average reach and special point-based methods in order to determine the rate of leakage in the bed (Hatch et al., 2010). These data were utilized to assess the variation in the hydraulic conductivity of the streambed over time, as a function of the canal and changes are related to sedimentation.

The point-by-point leakage rate, which was determined using the time series analysis of the thermal records of the streambed, shows leakage rates of 1.4 meters per day (moving to the lower parts and into the center). The leakage rates had changes in time and place, such that the leakage mostly is occurred in lower end of the reach and during summer and fall.

These results show that the interaction models of surface and groundwater can benefit from the relationships between the stream, sediment load and the hydraulic features of the streambed (Hatch et al., 2010).

In the study accomplished by Min et al. (2013), the scholars have focused on the spatial changes of the vertical hydraulic conductivity of a stream in a meandering river of China. They observed that the change in the vertical hydraulic conductivity of the stream along the reach of the river was remarkable and high amounts of $\mathrm{K}_{\mathrm{v}}$ is related to part of the canals with more deep water.

The evaluation of the 14 methods to determine the permeability was conducted through indirect measurement. The estimation of the value of hydraulic conductivity $\left(\mathrm{K}_{\mathrm{v}}\right)$ was done based on the distribution curve of particle measurement (Fenza et al., 2017). All the methods were evaluated with regard to certainty, by comparing the measured parameters and the results obtained from the permeation experiments. The findings demonstrated that the amounts of $\mathrm{K}_{\mathrm{v}}$ obtained from the distribution curves are smaller than the measured data, which could be due to the different depth of sediment sampling during the experimental analyses.

In this study, we analyzed the hydraulic conductivity during a one-year period. We tried to study the hydraulic conductivity of one area of a river during 52 weeks starting from January 20, 2017 and to see if we can come up with a formula to estimate the hydraulic conductivity during one year. Moreover, we extracted samples from the streambed at five different time intervals and sent them to the laboratory to analyze the changes in the grain size during the one-year time period. In addition, using experimental formulas, we measured the hydraulic conductivity and compared them with the data obtained using the stable permeation method. We reached an overall analysis about the interaction between the surface and groundwater.

\section{Materials and methods}

\section{Study area}

Ziyarat River, originating from Alborz mountain range, is located in Golestan Province, which is a northeastern area in Iran (Fig. 1). It flows to the north and after 
$36 \mathrm{~km}$, and merges into Gharesoo River. The drainage basin in upstream is about $100 \mathrm{~km}^{2}$ with dimensions of $19.64 \mathrm{~km}$ in length and $5.11 \mathrm{~km}$ in width. The mean of water abstraction rate at stream gauge is about $10.5 \mathrm{~m}^{2}$. The study area is located in a temperate climate. The mean of annual precipitation is equal to $601 \mathrm{~mm}$, and mean temperature is $13.4{ }^{\circ} \mathrm{C}$. The variation in seasonal precipitation is distinctive and not uniform. The temperature of stream water varies from 19.04 to $29.2{ }^{\circ} \mathrm{C}$. Although, the weather is rainier in winter, the majority of floods occur from August to November. The streambed sediments were alluvial coarse, sand-gravel, and clay and silt in downstream. The highest height of Ziyarat stream gauge is equal to $3068 \mathrm{~m}$ and the beginning of main river is $2620 \mathrm{~m}$. The length of the river to Naharkhoran is $21 \mathrm{~km}$ with the slop average rate of $10.1 \%$ and the remainder of river to Ghorbanabad is $15 \mathrm{~km}$ with the slop average rate of $4.6 \%$.

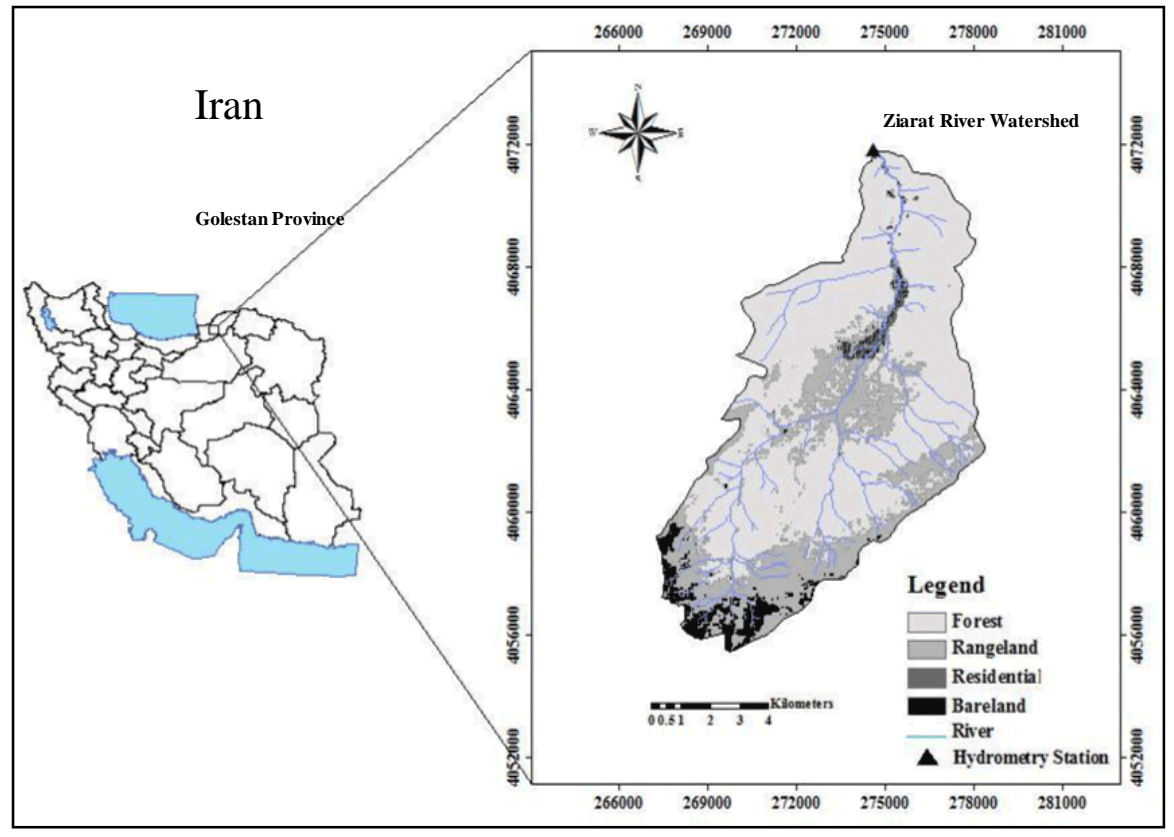

Figure 1. The location of the study area along the Ziarat River

The geographical position of the study area is shown based on latitude and longitude and the UTM coordinates system. It is evident that, most rivers stemming from the Alborz Mountain Range, are similar in terms of morphology and slope. Therefore, studying any of them can help us get familiar with other rivers of the same kind. In other words, the results of the study could be generalized to other rivers with alluvial bed. The area under study was located in downstream in Ghorbanabad, with a slope around $2 \%$. The position of the area, as identified by the UTM system, is X:271732,Y:4089803 (Fig. 2).

Since the interaction between the surface and groundwater in the bed rivers has been widely investigated and is considered significant, in this study, we examine the potential of groundwater layers in the downstream, as they satisfy the needs of human beings for water through wells. Another reason for selecting this part of the river is the decrease in the hydraulic conductivity of this area due to being located in the downstream. This results in sediments with small grain size consisted of silt which act like an 
impermeable layer. In addition, studying the downstream is an undeniable necessity, as this area is under the danger of flood during summer and this natural disaster overfills the streambed with sediments consisted of mud which thickens the impermeable layer in the bed of the river.
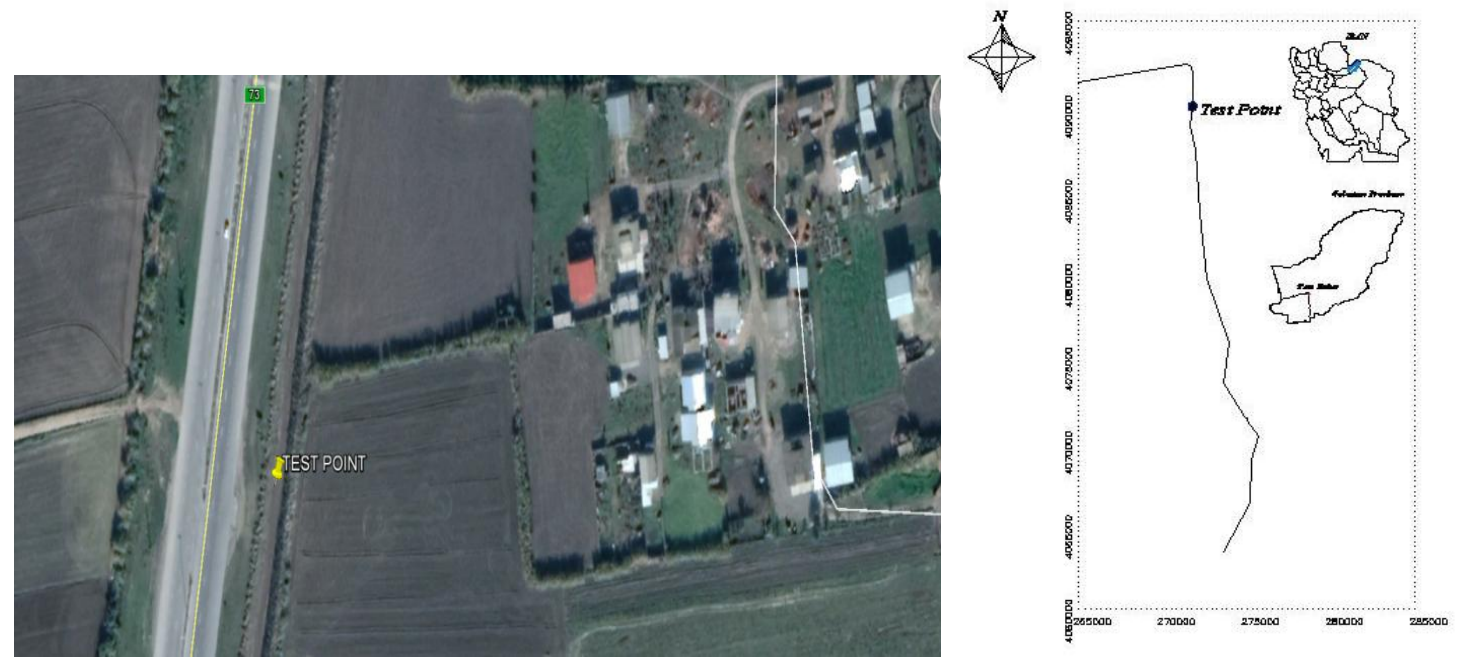

Figure 2. The location of the test point on the map

The high frequency of flood occurrence in the summer for this region is due to the fact that this area is located adjacent to the Alborz Mountains, within south zone and it is also close to the Caspian Sea, in the north zone, as a result the high heat leads to evaporation and the formation of rainy clouds due to the high volume of water evaporation during summer season. Hence, the reduction in the temperature renders this volume of water evaporation into the intensive rains. Moreover, due to the high heat of soil and secrecy of humid heat air in the soil holes, the intensive rains during summer reason cannot permeate into the soil holes and the accumulated water will flow which will lead to formation of flood.

\section{Methods}

\section{Vertical hydraulic conductivity}

Falling-head test method

A falling-head test is conducted by rapidly raising the water level in the control well and subsequently measuring the falling water level. Slug-in test is another term for falling-head test. In the previous studies, a field permeameter method has been adopted for measuring vertical hydraulic conductivity (see e.g. Chen, 2005; Genereux et al., 2008; Song et al., 2010; Dong et al., 2012). The purpose of this method is to determine the streambed hydraulic conductivity $\left(\mathrm{K}_{\mathrm{v}}\right)$, and, as it is illustrated in Figure 3, it operates by vertically inserting a pipe into the streambed, filling the pipe with water, and calculating the amount of decline of the water level inside the pipe. After repeating this process for a few times, the $\mathrm{K}_{\mathrm{v}}$ can be measured using this rate. In the present study, steel standpipe with an inner diameter of $4.8 \mathrm{~cm}$ and length of $120 \mathrm{~cm}$ was used. The pipe was injected into the sediments of the streambed and it was ensured that the length of the sediment column was almost equal to $40 \mathrm{~cm}$. A sensor (Onset HOBO Water 
Level-U20L-Series) with an accuracy of $1 \mathrm{~mm}$ was also employed to measure the water levels. Water was added during the test at the top of the pipe to create a hydraulic head. Then, the head was passed to fall in the pipe. In the current research, a water-level declining interval of $1 \mathrm{~cm}$ was used to record the hydraulic head and time. The hydraulic head estimations were obtained more than 3 times. To measure the $\mathrm{K}_{\mathrm{v}}$ value using Equation 1 proposed by Hvorslev (1951), all pairs of measured data of hydraulic head and time were used.

$$
K_{v}=\frac{\frac{\pi D}{M I m}+L_{V}}{t_{2}-t_{1}} \ln \left(h_{1} / h_{2}\right)
$$

Where $\mathrm{D}$ denotes the inner diameter of the pipe, $\mathrm{m}$ denotes the square root of the ratio of the horizontal conductivity $K_{h}$ represents the vertical conductivity $K_{v}$ (i.e., $\left.\mathrm{m}=\sqrt{\frac{K_{h}}{K V}}\right), \mathrm{L}_{\mathrm{v}}$ refers to the length of the sediment column, $\mathrm{h}_{1}$ and $\mathrm{h}_{2}$ are hydraulic head inside the pipe measured at times $t_{1}$ and $t_{2}$, respectively. Overall, $K_{h}$ is greater than $K_{v}$. An adopted Hvorslev (1951) solution has been proposed by Chen (2004) and Song et al. (2009) in order to specify the $\mathrm{K}_{\mathrm{v}}$ when $\mathrm{L}_{\mathrm{v}}$ is greater than $\mathrm{D}(E q .2)$ :

$$
K_{v}=\frac{L_{v}}{t_{2}-t_{1}} \ln \left(h_{1} / h_{2}\right)
$$

However, the error in $\mathrm{K}_{\mathrm{v}}$ from the formula provided by the modified formula of Hvorslev (1951). Equation 2 is related to the ratio $\left(\mathrm{L}_{\mathrm{v}} / \mathrm{D}\right)$ of the estimated sediment length $\left(\mathrm{L}_{\mathrm{v}}\right)$ to the inner diameter (D) of the steel pipe. When $1<\mathrm{m}<5$, if the ratio $\left(\mathrm{L}_{\mathrm{v}} / \mathrm{D}\right)$ is greater than 5 , the error of the adopted estimation will be less than $5 \%$ (Chen, 2004).

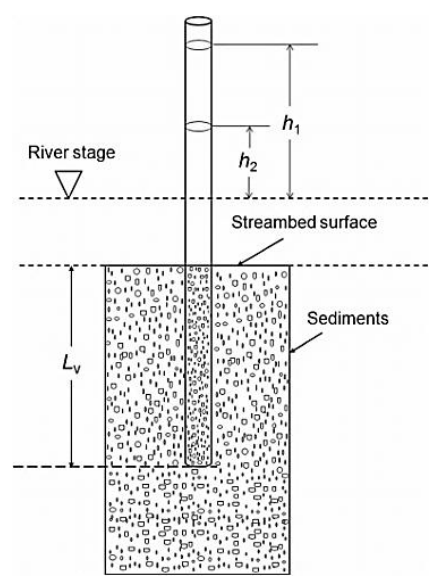

Figure 3. Schematic diagram showing an in situ permeameter test to determine streambed

The values of hydraulic conductivity were calculated weakly for this section of the river, in a regular manner and these values were analyzed in such a way that almost 52 values for hydraulic conductive were recorded during 52 weeks. 
Statistical analysis of the data for vertical hydraulic conductivity

The initial time series analysis shows that it has a decreasing trend and its data do not follow a normal distribution. The initial time series plot and the primary results of the data are presented in Figure 4 and Tables 1 and 2.

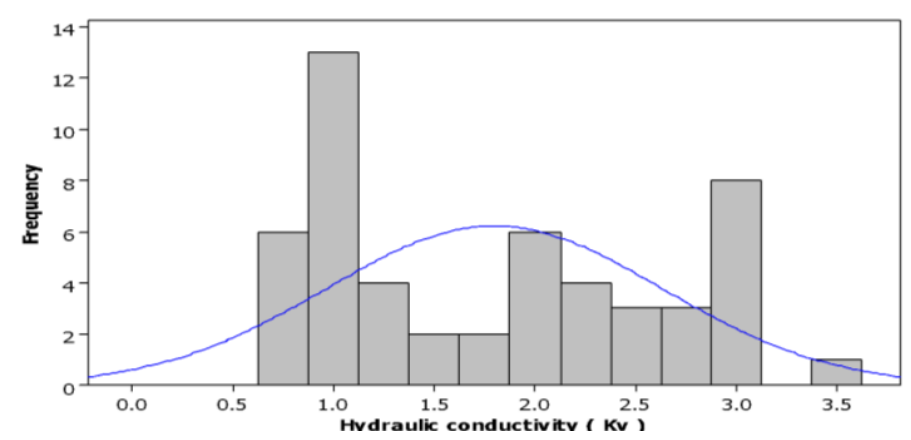

Figure 4. Histogram and Box diagram $\left(K_{v}\right)$ of Riverbed

Table 1. Values of $K_{v}$ within 52 weeks

\begin{tabular}{|c|c|c|c|}
\hline Time (week) & $\mathbf{K}_{\mathrm{v}}$ & Time (week) & $\mathbf{K}_{\mathbf{v}}$ \\
\hline 1 & 2.92 & 27 & 1.62 \\
\hline 2 & 2.27 & 28 & 1.70 \\
\hline 3 & 2.98 & 29 & 1.42 \\
\hline 4 & 2.16 & 30 & 1.12 \\
\hline 5 & 2.92 & 31 & 1.33 \\
\hline 6 & 2.98 & 32 & 1.34 \\
\hline 7 & 2.62 & 33 & 1.21 \\
\hline 8 & 3.56 & 34 & 1.02 \\
\hline 9 & 2.96 & 35 & 0.86 \\
\hline 10 & 2.15 & 36 & 0.98 \\
\hline 11 & 2.76 & 37 & 1.21 \\
\hline 12 & 2.96 & 38 & 0.99 \\
\hline 13 & 3.09 & 39 & 1.06 \\
\hline 14 & 1.96 & 40 & 0.98 \\
\hline 15 & 1.66 & 41 & 0.96 \\
\hline 16 & 2.86 & 42 & 0.78 \\
\hline 17 & 2.42 & 43 & 1.00 \\
\hline 18 & 2.98 & 44 & 0.98 \\
\hline 19 & 2.02 & 45 & 1.09 \\
\hline 20 & 2.62 & 46 & 0.88 \\
\hline 21 & 2.63 & 47 & 1.02 \\
\hline 22 & 2.02 & 48 & 0.70 \\
\hline 23 & 1.96 & 49 & 0.86 \\
\hline 24 & 2.26 & 50 & 1.02 \\
\hline 25 & 2.02 & 51 & 0.66 \\
\hline 26 & 2.05 & 52 & 0.74 \\
\hline
\end{tabular}


Table 2. Statistical parameters linked to $K_{v}$

\begin{tabular}{c|c|c|c|c|c}
\hline Mean & Minimum & Maximum & Std. Deviation & Kurtosis & Skewness \\
\hline 1.79 & .66 & 3.56 & .148 & -.947 & -.271 \\
\hline
\end{tabular}

\section{Verification of the hydraulic conductivity}

Researchers have made a lot of efforts and introduced the grain size analysis of the particles in the sediments of the streambed for the autocorrelation of the parameters that have a direct relationship with the hydraulic conductivity $\left(\mathrm{K}_{\mathrm{v}}\right)$ (Hazen, 1982; Rosas et al., 2014). Therefore, the hydraulic conductivity analysis of the streambed should be regarded as one of the methods to obtain the vertical hydraulic conductivity. Accordingly, the best method for sampling from the sediments of the bed is the vertical hydraulic conductivity to verify the process of sampling in the horizontal hydraulic conductivity $\left(\mathrm{K}_{\mathrm{v}}\right)$

\section{Sampling from the sediments of the streambed}

Since the present research aims at conducting a time history analysis on the hydraulic conductivity of a point of riverbed within one year, so the grain size of riverbed soil can be regarded as a proper parameter which has a high correlation with hydraulic conductivity. Therefore, a specific section of the river channel associated with river bed (at the afore-mentioned geographical length and width of X: 271732, Y: 4089803, in accordance with UTM coordination system) was opted and the results obtained for this section were compared with the values recorded for hydraulic conductivity of that section.

Since the sediments were soft in that part of the river, this task was done easily and the only point was ensuring that the device was operating properly.

A steel pipe was inserted $50 \mathrm{~cm}$ into the hyporheic zone in the bed of the river. A plastic pipe $(40 \mathrm{~cm})$ made of Polyvinyl chloride $(\mathrm{PVC})$ was inserted into this steel pipe where the particles of the sediments pile up. There was leather cover above the open part of the pipe which disconnected the pipe from the surrounding atmosphere. The sediments accumulate in the pipe remain unchanged and will not fall when the pipe is pulled out from the bed (Song et al., 2009).

These samples were sent to the soil mechanics laboratory of Golestan Province. The grain size experiment was conducted carefully and it was noted that the smallest grain was .075 and the largest one was $10 \mathrm{~mm}$. The particles smaller than .075 were identified as silt and clay and those between .075 and 2.0 were classified as sand. The grains larger than 2.0 were identified as gravel (Song et al., 2010).

\section{Results}

\section{Grain size analysis}

Grain size is the main controlling factor for streambed hydraulic conductivity (Song et al., 2010). Sampling from the sediments was accomplished in five sessions after obtaining the hydraulic conductivity. So, the analysis of grain size was done in weeks 1 , 6, 26, 47 and 52 . 
Indeed, the primary objective of this research was to extract sediment from intended section, middle section and endpoint section of the riverbed within the first week, 26-th week and 52-end week, respectively. This project was defined for grading analysis. That is, these three extractions within the above-mentioned weeks were pre-defined, while the research team decided to perform random sampling method on the riverbed particles within 6-th and 47-th weeks too. In fact, this mode of week selections meets the requirements of purposive and random sampling method.

The curve of grain size is depicted by Figure 5. This study attempted to analyze the changes in the sediments of the streambed during the three time intervals. It is evident that during 1 and 6 weeks, the curves of the grain size are quite similar and this was expected, since the hydraulic conductivity for these two weeks were the same. During the middle stages of the study, the curve of the grain size tended to the left in such a way that the percentage of sand increased and the percentage of gravel decreased. These variation in the grain size occurred with a decrease in the hydraulic conductivity. During weeks of 47 and 52, the percentage of silt and clay increased and the percentage of gravel decreased. As it was expected, the hydraulic conductivity decreased to a great extent. The percentages of silt, clay and sand of the sediments for these five specimens are given in Table 1. It is evident that due to the occurrence of floods during summer in this region, which caused great changes in the morphology of the streambed, the hydraulic conductivity of the bed started to decrease noticeably from 26-th week. The increase in the percentage of silt and clay is evident in the samples taken from 26-th week. $\mathrm{d}_{50}$ in Table 3 refers to the average diameter of particles of the sediments in millimeter the weight of which is less than $50 \%$ of the overall particles.

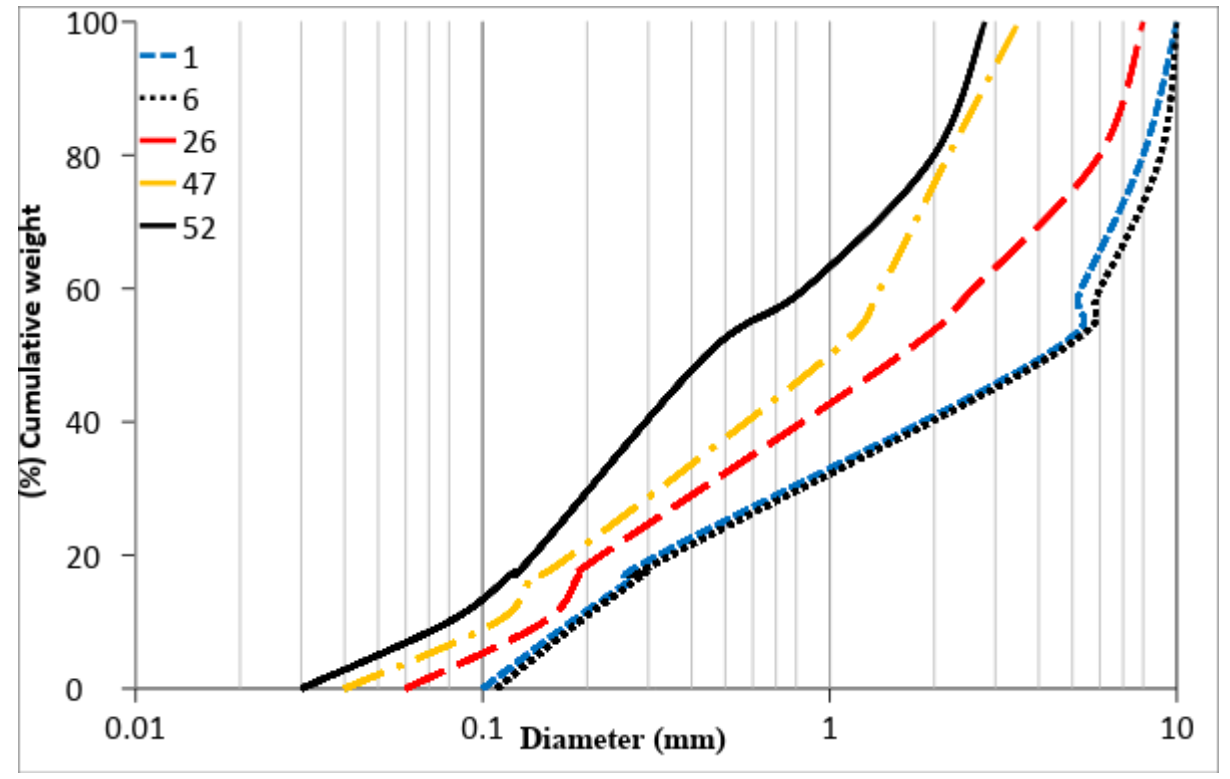

Figure 5. Curve of grading distribution of the sediment fines of riverbed within selected five weeks

The first step in the analysis of time series data is drawing the variable values during the period under investigation. This is influential in identifying the trends of the data which need to be extracted from the data before doing the analysis. Figure 6 shows the values of the $\mathrm{K}_{\mathrm{v}}$ index during the 52 weeks period which was analyzed by MINITAB 18 
Software. To determine the trend of the data, which is a descending trend, as the diagram demonstrates, the different visual functions, the second step and the S curve were evaluated. The results indicate that the $S$ curve exhibited the best fitness for the trend of the data. The functional format of this curve is shown in Equation 3:

$$
y_{t}=\frac{\alpha}{\beta+\gamma\left(\delta^{t}\right)}
$$

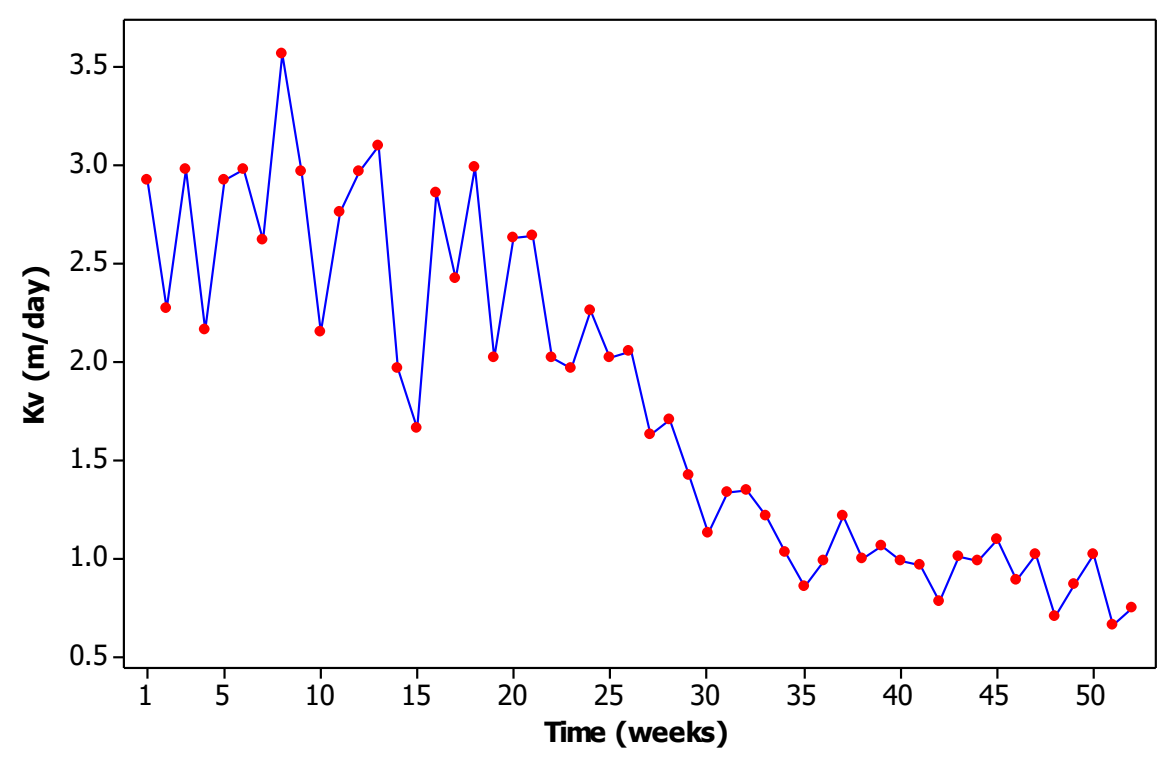

Figure 6. Time series diagram of $K_{v}$ within 52 weeks

Table 3. Grading distribution of 5 samples of particles within riverbed over a year

\begin{tabular}{c|c|c|c|c|c}
\hline Sample number & Sample 1 & Sample 2 & Sample 3 & Sample 4 & Sample 5 \\
\hline Per week & 1 & 6 & 26 & 47 & 52 \\
\hline \% < 2 mm & 40.4 & 41.5 & 52.2 & 78.6 & 80.4 \\
\hline $\begin{array}{c}\text { \% }<\mathbf{0 . 0 7 5} \mathbf{~ m m} \\
\text { (silt and clay \%) }\end{array}$ & 0 & 0 & 2.1 & 6.3 & 8.1 \\
\hline $\begin{array}{c}\text { Average median grain size } \\
\mathbf{d}_{\mathbf{5 0}}(\mathbf{m m})\end{array}$ & 4.1 & 4.2 & 1.4 & 1 & 0.42 \\
\hline
\end{tabular}

The $\alpha, \beta, \gamma$, and $\delta$ parameters were estimated by the data and the values of the $\mathrm{y}_{\mathrm{t}}$ trend were subtracted from the main values of the data. The remaining data from this section will be analyzed as the detrended data using the time series models. The values of the trend under this function are shown over the main values of the data. As it can be seen in Figure 7, Equation 4 obtained from the fitness analysis is as follows: 


$$
y_{t}=\frac{100}{5.43+23.69\left(1.033^{t}\right)}
$$

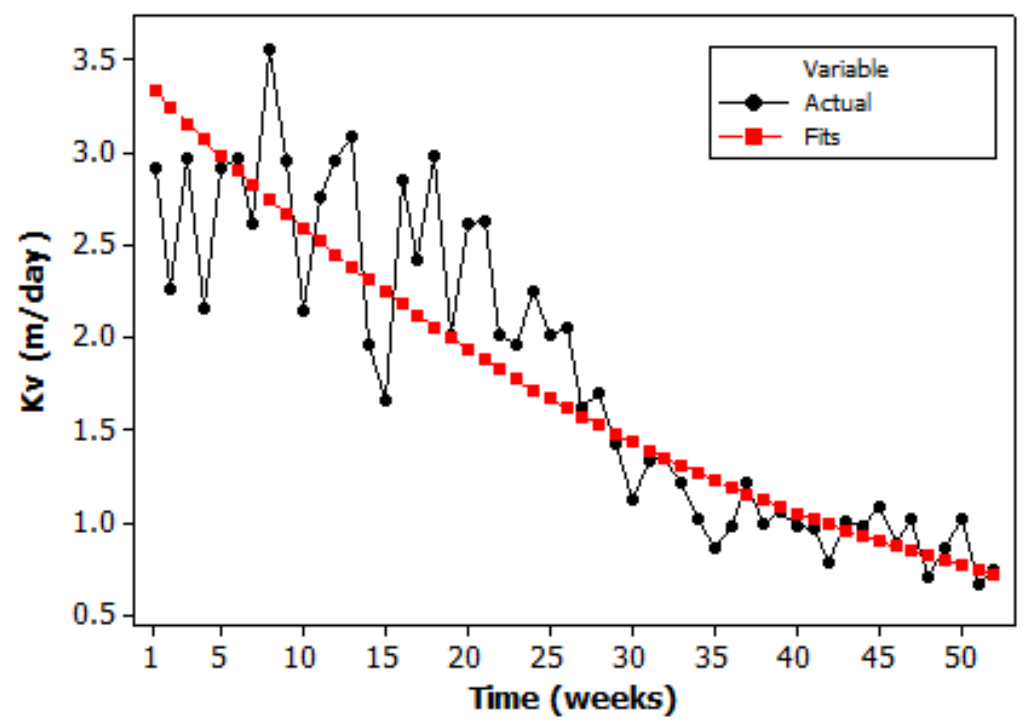

Figure 7. Identifying the time series trend $\left(K_{v}\right)$ under $S$ curve

After identifying the trends in the time series data, the first step in recognizing the model is to determine the values of autocorrelation. For this purpose, the values of ACF and PACF were calculated and drawn for the ACF and PACF of detrended data of 13 intervals which were identified automatically with reference to the length of the data. Figures 8 and 9 show the values of ACF and PACF of detrended data $\left(\mathrm{K}_{\mathrm{v}}\right)$, respectively.

As can be seen in Figures 8 and 9, the values of autocorrelation and partial autocorrelation of the data were insignificant only in the first interval which is an indication the fact that ARMA model with $(1,1)$ parameters is fitted. To analyze the values more accurately, the statistics of their significance level which have the Student's t-distribution are also given in Table 4.

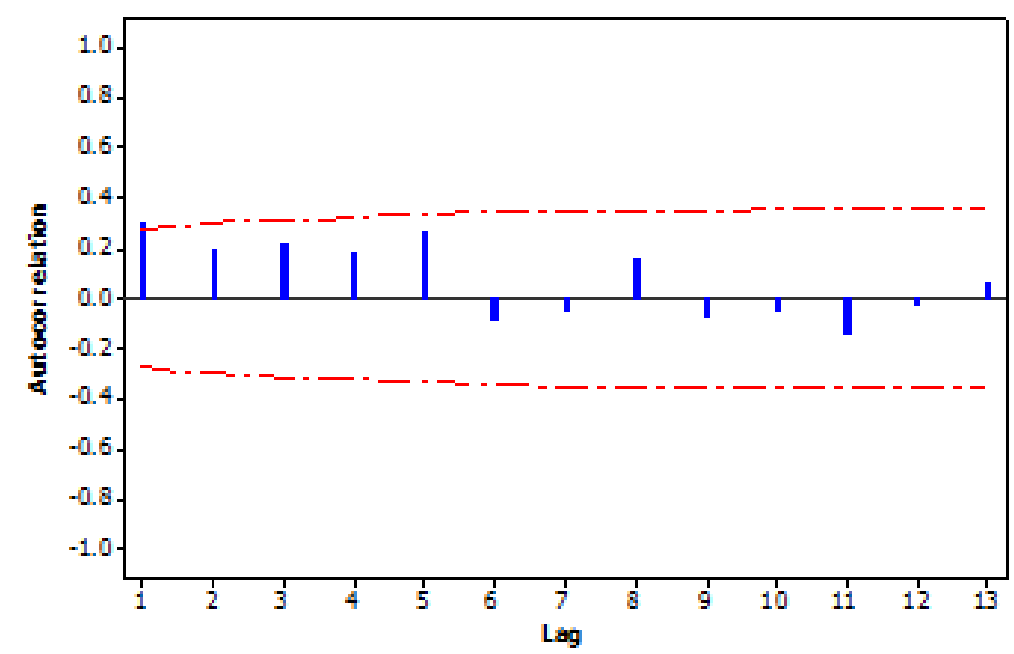

Figure 8. Autocorrelation values of $(A C F)$ detrended hydraulic conductivity 


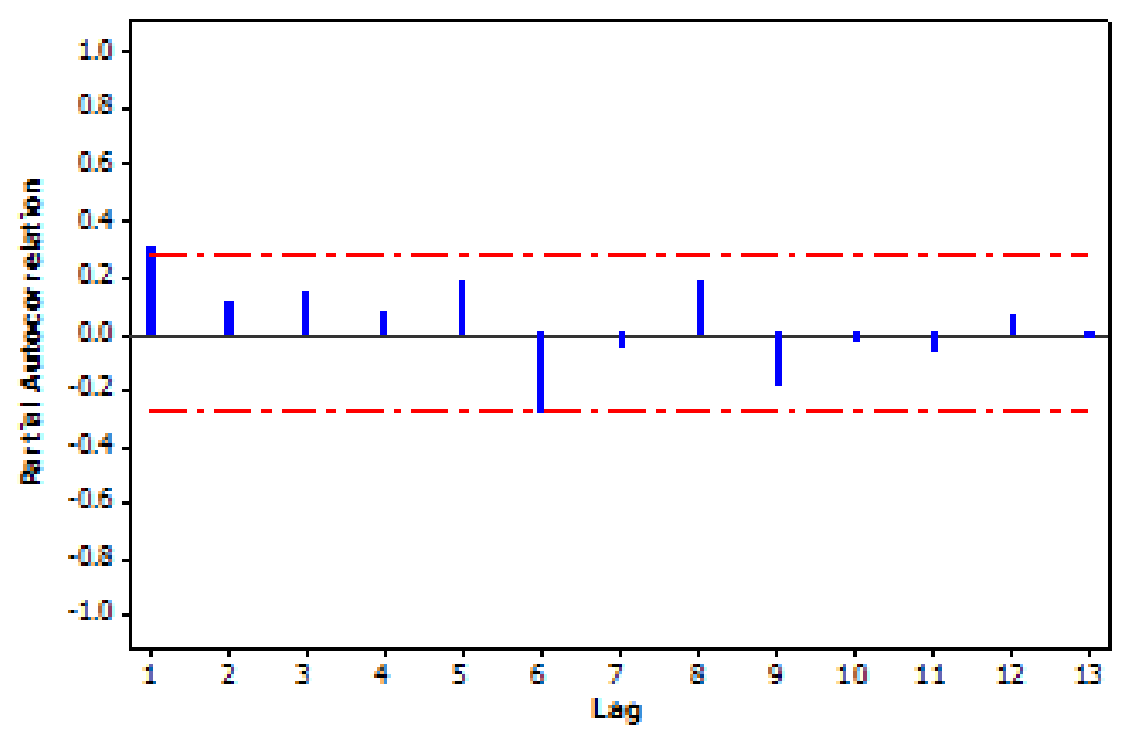

Figure 9. Partial autocorrelation values (PACF) of detrended hydraulic conductivity

Table 4. Values of autocorrelation and partial autocorrelation of detrended data

\begin{tabular}{c|c|c|c|c|c}
\hline Interruption & Autocorrelation & T Static & $\begin{array}{c}\text { Partial } \\
\text { autocorrelation }\end{array}$ & T Static & $\begin{array}{c}\text { Ljung-Box } \\
\text { statistic }\end{array}$ \\
\hline 1 & 0.302403 & 2.18 & 0.302403 & 2.18 & 5.03 \\
\hline 2 & 0.187394 & 1.24 & 0.105604 & 0.76 & 7.01 \\
\hline 3 & 0.214519 & 1.38 & 0.146813 & 1.06 & 9.64 \\
\hline 4 & 0.181128 & 1.13 & 0.079277 & 0.57 & 11.56 \\
\hline 5 & 0.264257 & 1.6 & 0.182559 & 1.32 & 15.74 \\
\hline 6 & -0.08194 & -0.47 & -0.27918 & -2.01 & 16.15 \\
\hline 7 & -0.0496 & -0.29 & -0.04806 & -0.35 & 16.3 \\
\hline 8 & 0.159692 & 0.92 & 0.179708 & 1.3 & 17.93 \\
\hline 9 & -0.07248 & -0.41 & -0.17439 & -1.26 & 18.27 \\
\hline 10 & -0.04918 & -0.28 & -0.02614 & -0.19 & 18.43 \\
\hline 11 & -0.14704 & -0.83 & -0.05485 & -0.4 & 19.91 \\
\hline 12 & -0.0151 & -0.08 & 0.065661 & 0.47 & 19.93 \\
\hline 13 & 0.055656 & 0.31 & -0.00882 & -0.06 & 20.15 \\
\hline
\end{tabular}

According to the results given in Table 5, it is evident that in the first interval both $\mathrm{ACF}$ and PACF were significant. The value of Ljung-Box, which was found to be equal to 5.03, shows the suitability of the first interval for the self-recursion sections and the average dynamic model.

To determine the optimum model among all the possible models which have parameters equal to the suggested values in the diagrams of ACF and PACF, the average square values of the model errors in data prediction were taken into account. Accordingly, models with different parameters were fitted for the data and the average square values of the model errors were compared and contrasted. In addition, since estimating the time series models results in error values in the model, the primary 
assumptions of the models (normality, equal variance, and independence) need to be checked. Among all the fitted models, most did not have desirable models as far as the primary assumptions were concerned. The statistics of the Ljung-Box test were also evaluated to check the information in the model error and, accordingly the model which significantly caused pure noises was selected. The ARMA model $(1,1)$ consisted of one self-recursion term and one term of dynamic average.

\section{Validation of the model}

Taking into account the details of the model fitness, it can be seen that the selfrecursion term in the first step of the time series model and the dynamic average component of the model were significant, so the index of $\mathrm{K}_{\mathrm{v}}$ is significantly affected by the first interval. After fitting the model, determining the accuracy of the selected pattern is necessary. The root-mean-square error (RMSE) was used in this model. The mean square error for this model was found to be equal to .1357, which, compared to other estimated models, had an acceptable value. The criterion of the root-mean-square error (RMSE) was estimated based on Equation 5.

$$
R M S E=\left[\frac{\sum_{i=1}^{n}\left(P_{i}-o_{i}\right)^{2}}{n}\right]^{1 / 2}
$$

In Equation 5, n refers to the number of cases given to the model. Oi and Pi refer to the values of measurement and estimation, respectively.

\section{Discussion}

\section{Checking the suitability of the model}

One of the methods to analyze the residuals is analyzing the diagrams of the residuals. Accordingly, the first step is to check the normality of the residuals. Figure $10 a$ shows that the error components are normally distributed. The histogram (Fig. 10c) also depicts that the residuals are normally distributed. The distribution of error values versus the fitted values shows that the expanded and contracted trends do not exist in this diagram. Accordingly, the error statements were independent from each other.

In order to determine the equal variance of the error components, the values of error were plotted based on the order of their occurrence (Fig. 10b). In this figure, it seems that the primary statements of error have more variance but this variance has not been different over time. Therefore, it is possible to consider the converting models like the MSM model as more suitable for these data than the ARMA or ARIMA models.

ARIMA model is considered as one of the best prediction models used for short-term time series analysis (Chang et al., 2012). In addition, the Holt-Winters time series analysis can be used when there exist seasonal or cyclic variation. Costa et al. (2015) have attempted to estimate the water qualitative parameters using Holt-Winters model whose findings have demonstrated the model efficiency. However, it is should be noted that models like Holt-Winters lead to greater error, compared to ARIMA Model. The diagram of the residuals versus time show that they are around zero with a fixed variance (Fig. 10d). 


\section{The Pert-Manto test}

A more formal method to examine the suitability of the model is the Pert-Manto test. This test is given at the end of all the outputs of the model fitness. This method is known as the Ljung-Box Test in the statistical software. The significance level of Ljung-Box statistics in this model is greater than the .05 error for the intervals of 12,24 , 36, and 48 (Table 5). This shows that there were not significant variations in the error statements for the modelling and the assumption that the residuals were not correlated, is confirmed. The primary assumptions of the error statements in the model are checked in Figure 10. Figure 11 illustrates the fit values of $\mathrm{K}_{\mathrm{v}}$ in the model in contrast to their real values. It seems that the obtained time series model can suitably explain the trend and changes existent in the data.

(a)

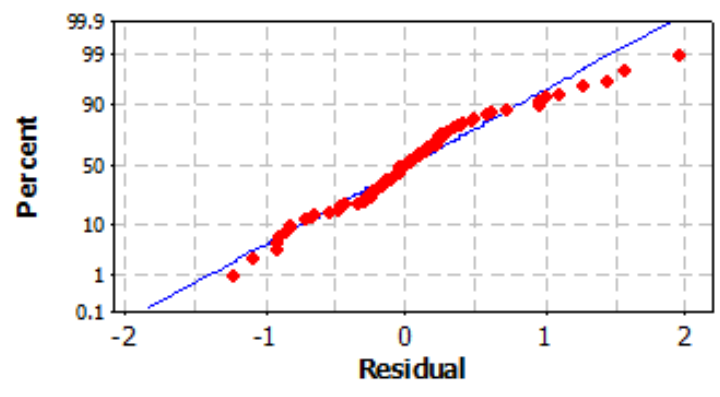

(c)

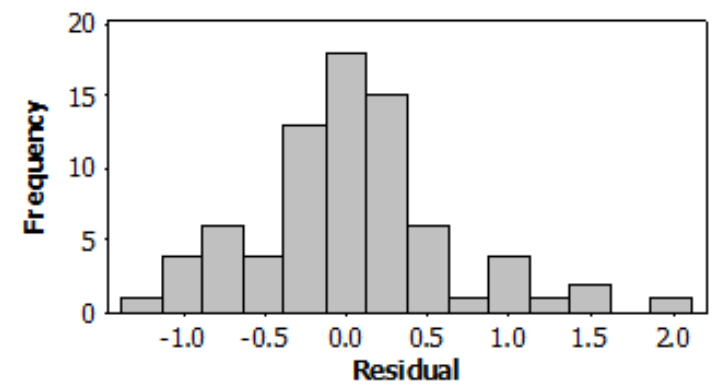

(b)

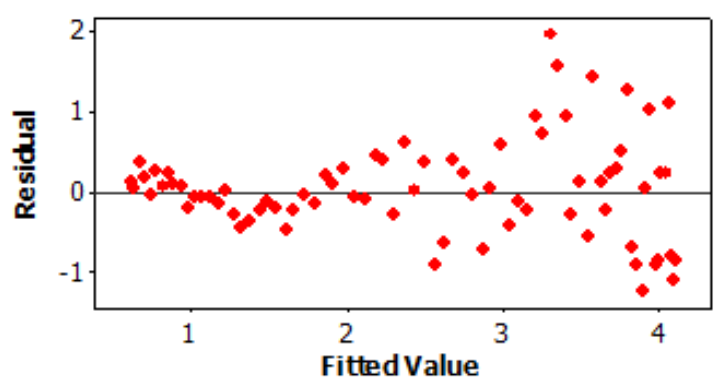

(d)

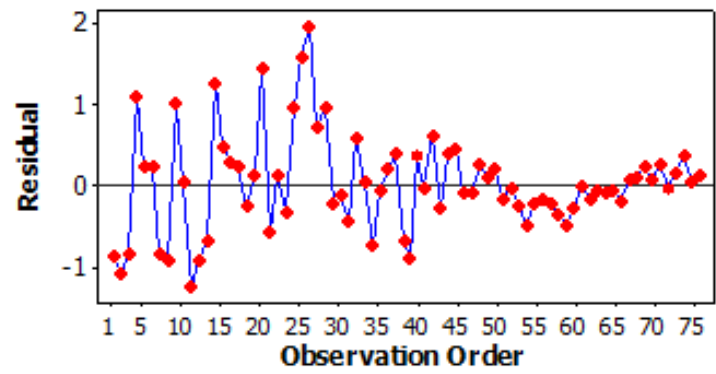

Figure 10. Primary assumptions of model error terms. a Normality diagram. $\boldsymbol{b}$ Residual versus fitted values. $\boldsymbol{c}$ Histogram diagram. $\boldsymbol{d}$ Residual versus time

Table 5. Results of Ljung-Box test

\begin{tabular}{c|c|c|c|c}
\hline Delay time & 12 & 24 & 36 & 48 \\
\hline Chi Square & 14.2 & 29 & 32.6 & 37 \\
\hline Freedom degree & 9 & 21 & 33 & 45 \\
\hline P-Value & 0.117 & 0.114 & 0.486 & 0.797 \\
\hline
\end{tabular}

To determine the goodness of fit and ensure that error statements of the model do not have any information, the diagrams of ACF and PACF were plotted for the components of the model error (Figs. 12 and 13). 


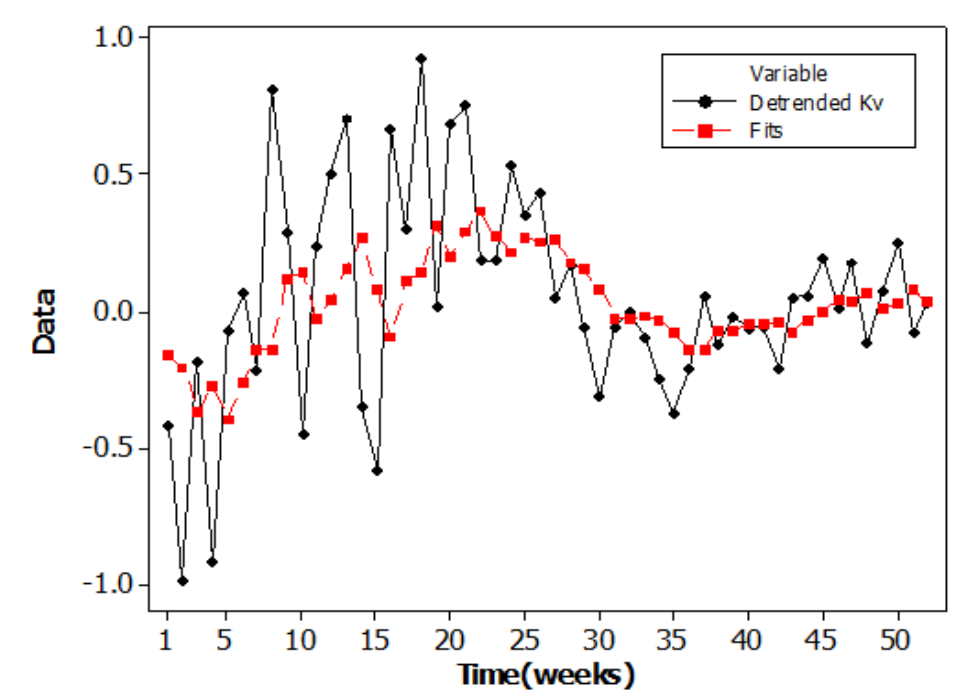

Figure 11. Fitted values versus detrended real values of $K_{v}$

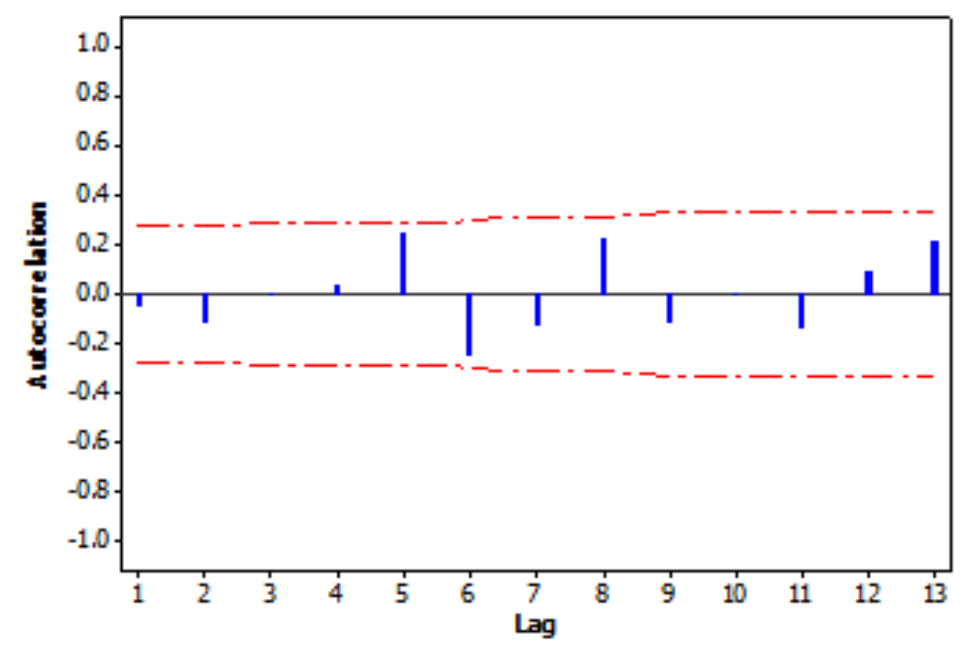

Figure 12. Values of ACF function for model error elements

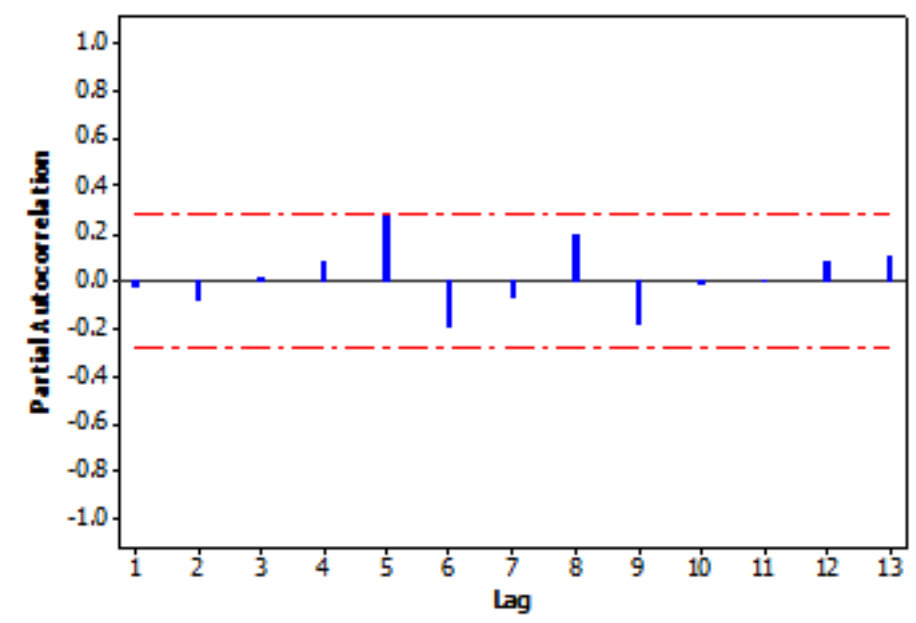

Figure 13. Values of PACF function for model error elements

APPLIED ECOLOGY AND ENVIRONMENTAL RESEARCH 16(4):4311-4327. http://www.aloki.hu • ISSN 15891623 (Print) • ISSN 17850037 (Online) DOI: http://dx.doi.org/10.15666/aeer/1604_43114327 (c) 2018, ALÖKI Kft., Budapest, Hungary 
The results showed that in all the intervals, these two indices were significant and the errors obtained from the model were around zero and no further information was available for modelling. Therefore, the assumption of independence of the residuals was accepted.

With reference to the suitable fitness of the model, the predicted values of $K_{v}$ which were added to the trend values in the next steps and show the main predicted values for the $\mathrm{K}_{\mathrm{v}}$ index during the following 52 weeks. Figure 14 shows the predicted values by the model for $\mathrm{K}_{\mathrm{v}}$. However, with a closer examination and analysis of the impact and role of major factors on $\mathrm{K}_{\mathrm{v}}$, such a prediction is not very optimistic. Therefore, considering the next flood and its effect on the river bed layers, it is likely to expect quite surprising results on the time series model so that the flood phenomenon can be considered as a direct shocking factor for the time series model.

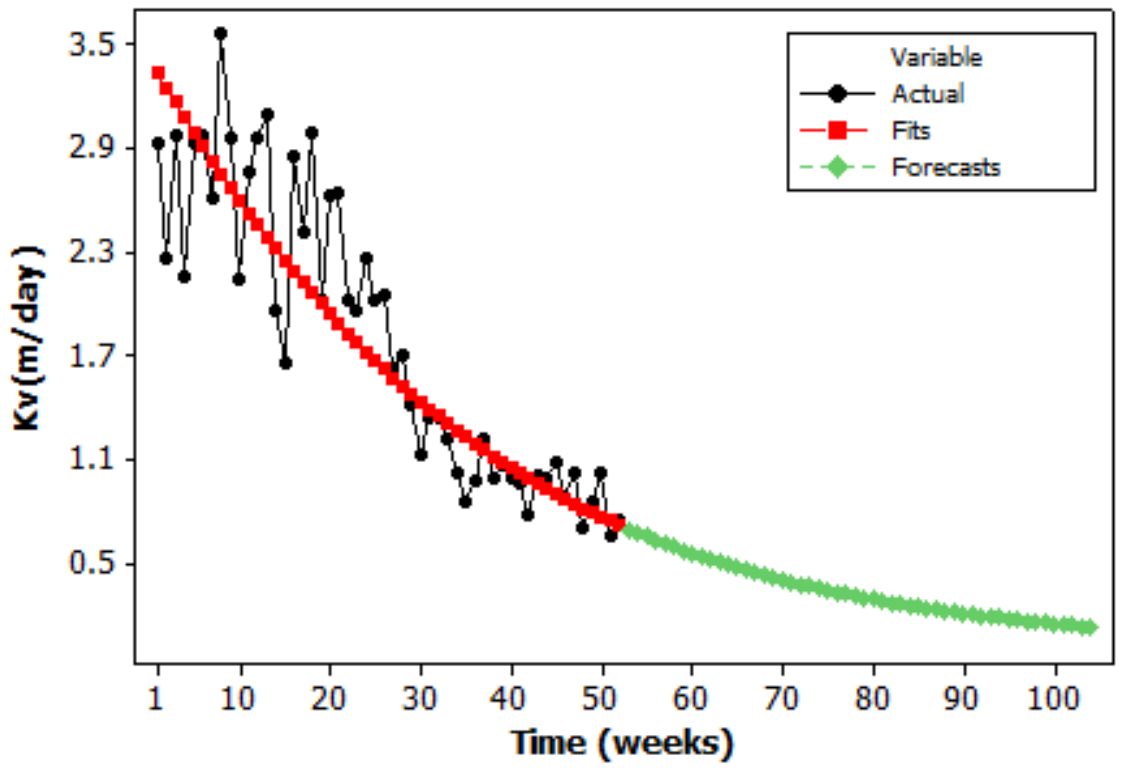

Figure 14. Identifying the time series trend $\left(K_{v}\right)$ for the next 52 weeks

Unfortunately, there is little information about time series analysis of the hydraulic conductivity of the riverbed. For instance, Genereux et al. (2008) have focused on West Bear River, located at North Carolina, USA and the significant variation of the river within all 46 zones with 262 interval were measured in bimonthly manner. However, it is worth noting the investigation of hydraulic conductivity per two months cannot yield promising results and the resulted trend cannot be desirable in terms of predicting the hydraulic conductivity, while in our research, the measurements were done every 7 days. Wu et al. (2015) found that, after the flood season, the influence of bed-form on streambed $\mathrm{K}_{\mathrm{v}}$ values was small, compared to that of the flood season. In the present study, it was observed that bed form of the river has a great impact on the hydraulic conductivity values prior to flood occurrence, and this finding is in line with that of $\mathrm{Wu}$ et al. (2015). It can be deduced that the impermeable layer consisted of silt and clay particles emerging within the river bed after flood, can affect everything, while the impact of other factors on the values of hydraulic conductivity is negligible (e.g. bedform). 
It should be pointed out that the estimation of hydraulic conductivity of a specific zone of a river within a time can yield useful information on the exchange rate of surface and subsurface water. Moreover, time series analysis is a cost-effective solution for estimating the hydraulic conductivity. So the behavior of specific zone of a riverbed can provide us with relatively general information about river. For instance in the present paper, the influence of flood on degradation intensity of hydraulic conductivity was revealed and it can be inferred that the flood encompasses the riverbed with impermeable layer comprised of silt and clay particles, as a result the exchange rate of surface and subsurface water will decrease.

\section{Conclusion}

The time series analysis of hydraulic conductivity is one of the new methods to predict the trend of estimating the interaction between the surface and groundwater which helps human beings protect the rivers against natural disasters. Consequently, this study conducted a time series analysis to examine the hydraulic conductivity of one part of the downstream in Ziarat River in Gorgan, Iran. First, the data of hydraulic conductivity were verified and after identifying the trends, the values of autocorrelation and partial autocorrelation were determined. Finally, the ARMA model $(1,1)$ was identified as the best model, but some external variables like flood were effective in the variation of hydraulic conductivity which led to evident changes in the morphology of the streambed and noticeably reduced the hydraulic conductivity. A look at the weather forecasts for this region shows the occurrence of flood in late July or August, but due to the inaccurate prediction of the flood, a variable that reduces the hydraulic conductivity is impossible. Considering the growing impact of major factors on $\mathrm{K}_{\mathrm{v}}$ such as flood, It can be mentioned that predicting the hydraulic conductivity is difficult so it is suggested that time series analysis be performed in a period of 3 to 5 years. The obtained results can be generalized to other rivers of the same type, which have the same morphological conditions or annually experience one or more flood.

\section{REFERENCES}

[1] Cardenas, M. B., Wilson, J. L., Zlotnik, V. A. (2004): Impact of heterogeneity, bed forms, and stream curvature on subchannel hyporheic exchange. - Water Resources Research 40(8).

[2] Chang, X., Gao, M., Wang, Y., Hou, X. (2012): Seasonal autoregressive integrated moving average model for precipitation time series. - Journal of Mathematics and Statistics 8(4): 500-505.

[3] Chen, X. (2004): Streambed hydraulic conductivity for rivers in south-central Nebraska. JAWRA Journal of the American Water Resources Association 40(3): 561-573.

[4] Chen, X. (2005): Statistical and geostatistical features of streambed hydraulic conductivities in the Platte River, Nebraska. - Environmental Geology 48(6): 693-701.

[5] Costa, M., Gonçalves, A. M. Silva, J. (2015): Forecasting time series combining HoltWinters and bootstrap approaches. - In: Proceedings of the International Conference on Numerical Analysis and Applied Mathematics, 23-29 September 2015, Rhodes, Greece.

[6] Dong, W., Chen, X., Wang, Z., Ou, G., Liu, C. (2012): Comparison of vertical hydraulic conductivity in a streambed-point bar system of a gaining stream. - Journal of Hydrology 450: 9-16. 
[7] Fenza, P., Da Pelo, S., Buttau, C., Vacca, S., Ghiglieri, G. (2017): Testing indirect methods to infer hydraulic conductivity in streambed sediments: preliminary results. Flowpath 2017.

[8] Genereux, D. P., Leahy, S., Mitasova, H., Kennedy, C. D., Corbett, D. R. (2008): Spatial and temporal variability of streambed hydraulic conductivity in West Bear Creek, North Carolina, USA. - Journal of Hydrology 358(3-4): 332-353.

[9] Hatch, C. E., Fisher, A. T., Ruehl, C. R., Stemler, G. (2010): Spatial and temporal variations in streambed hydraulic conductivity quantified with time-series thermal methods. - Journal of Hydrology 389(3-4): 276-288.

[10] Hazen, A. (1892): Some physical properties of sands and gravels: mass. - State Board of Health Annual Report 1892: 539-556.

[11] Hvorslev, M. J. (1951): Time lag and soil permeability in ground-water observations. Waterways Experiment Station, US Army Bull 36, US Army Corps of Engineers, Vicksburg, MI, 50 pp Creek, North Carolina, USA. - Journal of Hydrology 358: 332-353.

[12] Min, L., Yu, J., Liu, C., Zhu, J., Wang, P. (2013): The spatial variability of streambed vertical hydraulic conductivity in an intermittent river, northwestern China. Environmental Earth Sciences 69(3): 873-883.

[13] Rosas, J., Lopez, O., Missimer, T. M., Coulibaly, K. M., Dehwah, A. H., Sesler, K., Lujan, L. R. Mantilla, D. (2014): Determination of hydraulic conductivity from grain-size distribution for different depositional environments. - Groundwater 52(3): 399-413.

[14] Saenger, N., Kitanidis, P. K., Street, R. L. (2005): A numerical study of surface-subsurface exchange processes at a riffle-pool pair in the Lahn River, Germany. Water Resources Research 41(12).

[15] Song, J., Chen, X., Cheng, C., Wang, D., Lackey, S., Xu, Z. (2009): Feasibility of grainsize analysis methods for determination of vertical hydraulic conductivity of streambeds. - Journal of Hydrology 375(3-4): 428-437.

[16] Song, J., Chen, X., Cheng, C., Wang, D., Wang, W. (2010): Variability of streambed vertical hydraulic conductivity with depth along the Elkhorn River, Nebraska, USA. Chinese Science Bulletin 55(10): 992-999.

[17] Storey, R. G., Howard, K. W., Williams, D. D. (2003): Factors controlling riffle-scale hyporheic exchange flows and their seasonal changes in a gaining stream: A three-dimensional groundwater flow model. - Water Resources Research 39(2).

[18] Wu, G., Shu, L., Lu, C., Chen, X., Zhang, X., Appiah-Adjei, E. K., Zhu, J. (2015): Variations of streambed vertical hydraulic conductivity before and after a flood season. Hydrogeology Journal 23: 1603-1615. 